\title{
Retraction Note to: Stress Sensitivity of Loose Sandstone and Sports Training Management Based on Image Recognition
}

\author{
Mu Jiang ${ }^{1} \cdot$ Xiaoying Zhang $^{2}$ \\ Published online: 4 November 2021 \\ (c) Saudi Society for Geosciences 2021
}

Retraction Note to: Arabian Journal of Geosciences (2021) 14: 1545 https://doi.org/10.1007/s12517-021-08006-1

The Editor-in-Chief and the Publisher have retracted this article because the content of this article is nonsensical. The peer review process was not carried out in accordance with the Publisher's peer review policy. The authors have not responded to correspondence regarding this retraction.

The original article can be found online at https://doi.org/10.1007/ s12517-021-08006-1.

Xiaoying Zhang

jm331415@163.com

1 University Sports Department, Nanjing University

of Information Science and Technology, Nanjing 210044,

China

2 Department of Physical Education, Guangdong Medical

University, Dongguan 523808, China 